\title{
MODEL STRATEGI E-LEARNING TERHADAP MOTIVASI BELAJAR MAHASISWA DI MASA WABAH COVID-19
}

\author{
Granit Agustina ${ }^{1}$ \\ Universitas Pendidikan Indonesia \\ granit82.GA@gmail.com \\ Syamsu Yusuf $\mathrm{LN}^{2}$ \\ Universitas Pendidikan Indonesia \\ syamsu@upi.edu \\ Rudi Suprianto Ahmadi ${ }^{3}$ \\ Universitas Winaya Mukti \\ rudiahmadi64@gmail.com \\ Feby Febrian ${ }^{4}$ \\ Universitas Winaya Mukti \\ obelix9009@gmail.com
}

\begin{abstract}
Abstrak - Penelitian ini bertujuan untuk menganalisis metode pembelajaran daring terhadap motivasi belajar mahasiswa pada masa wabah covid-19 di lingkungan Fakultas Ekonomi dan Bisnis Universitas Winaya Mukti. Kondisi Pembelajaran Online dengan menggunakan e-learning pada atmosfir pendidikan tinggi memiliki maksud pengembangan cara belajar dengan online yang berbasis teknologi informasi dan selama ini telah berjalan pada perguruan tinggi. Guna mengembangkan proses pembelajaran yang selama ini sudah berlangsung antara mahasiswa dan dosen secara khusus di kembangkan cara-cara atau metode transfer pengetahuan dalam berbagai mata kuliah secara daring. Penelitian dilakukan dengan menggunakan kuesioner yang di bagikan kepada seluruh mahasiswa dan mahasiswi Fakultas Ekonomi dan Bisnis Universitas Winaya Mukti dengan menggunakan fasilitas google form. Metode penelitian ini menggunakan regresi linier dan korelasi pearson. Pengolahan data dilakukan dengan menggunakan SPSS 22 for windows. Dari hasil penelitian diketahui bahwa hubungan pembelajaran daring selama covid 19 terhadap motivasi belajar mahasiswa sebesar 0.553, hal ini menunjukkan bahwa metode pembelajaran daring memiliki pengaruh positif signifikan terhadap motivasi belajar mahasiswa pada masa covid-19. Manfaat dari penelitian ini dapat memberikan kontribusi positif bagi pengembangan metode pembelajaran daring dalam menumbuhkan motivasi belajar mahasiswa.
\end{abstract}

Kata kunci: E-learning, Motivasi Belajar,. 
Abstract - This study aims to analyze online learning methods on student learning motivation during the covid-19 outbreak in the Faculty of Economics and Business, University of Winaya Mukti. Conditions of Online Learning by using e-learning in the atmosphere of higher education have the intention of developing ways to learn online based on information technology and so far has been running on universities. In order to develop the learning process that has been ongoing between students and lecturers in particular developed ways or methods of transferring knowledge in various online courses. The study was conducted using a questionnaire that was distributed to all students of the Faculty of Economics and Business, University of Winaya Mukti using the Google form facility. This research method uses linear regression and Pearson correlation. Data processing is performed using SPSS 22 for windows. From the results of the study note that the relationship of online learning during covid 19 to student learning motivation of 0.553 , this shows that online learning methods have a significant positive effect on student learning motivation during covid-19. The benefits of this research can make a positive contribution to the development of online learning methods in growing student motivation.

Keywords: E-learning, Learning Motivation

\section{PENDAHULUAN}

Pendidikan merupakan kegiatan yang kompleks, dan meliputi berbagai komponen yang berkaitan erat satu sama lain (sutrisno, 2016). Oleh sebab itu, apabila pendidikan ingin dilaksanakan secara terencana dan teratur, maka berbagai faktor yang terlibat dalam pendidikan harus dipahami terlebih dahulu. Berbagai komponen dalam sistem pendidikan, baik secara mikro maupun dalam kajian makro perlu dikenali secara mendalam sehingga komponen-komponen tersebut dapat difungsikan dan dikembangkan guna mengoptimalkan garapan pendidikan tersebut ke arah pencapaian tujuan pendidikan yang ditetapkan (dinn wahyudi dkk, 2006).

$$
\text { Menurut budiman }
$$

Perkembangan teknologi informasi yang semakin pesat di era globalisasi saat ini tidak bisa dihindari lagi pengaruhnya terhadap dunia pendidikan. Tuntutan global menuntut dunia pendidikan untuk selalu dan senantiasa menyesuaikan perkembangan teknologi terhadap usaha dalam peningkatan mutu pendidikan, terutama penyesuaian penggunaan teknologi informasi dan komunikasi bagi dunia pendidikan khususnya dalam proses pembelajaran. Salah satu cara dalam meningkatkan kualitas pendidikan adalah dengan cara mengikuti perkembangan kemajuan teknologi agar tidak terjadi gap antara pendidikan dan teknologi yang berkembang pesat saat ini. Berbagai cara yang dapat dilakukan dalam mengurangi gap antara pendidikan dan teknologi, salah satunya dengan memanfaatkan media teknologi dalam melakukan proses pembelajaran.

Perkembangan teknologi yang semakin pesat terutama dalam kaitannya dengan revolusi industri 4.0 adalah perkembangan teknologi informasi, dimana dengan berkembangnya teknologi informasi menuntut kita untuk dapat menggunakan dan memanfaatkan teknologi informasi sebaik mungkin dalam 
berbagai hal, tidak terkecuali dalam hal pendidikan dan pengajaran di lingkungan universitas. Salah satu penerapan teknologi sebagai media dalam pendidikan dan pengajaran adalah penggunaan fasilitas elektronik berupa web dimana dengan menggunakan web kita dapat memperoleh berbagai informasi yang dibutuhkan.

Kondisi saat ini dengan merebaknya wabah penyakit covid-19 menuntut dunia pendidikan untuk merubah pola pendidikan pengajaran dari tradisional tatap muka menjadi menggunakan fasilitas teknologi informasi yang saat ini berkembang pesat. Penggunaan teknologi ini menuntut kemampuan yang lebih dari dosen maupun mahasiswa untuk dapat memaksimalkan proses pengajaran yang dalam kondisi saat ini merupakan satusatunya alternatif pembelajaran yang dapat digunakan.

E-Learning merupakan sebuah teknologi yang mampu membuat modifikasi dalam proses pembelajaran sehingga dengan menggunakan $\mathrm{E}$ Learning mahasiswa mampu memiliki pengetahuan dasar tentang teknologi yang sangat berguna untuk mencapai tujuan pendidikan dan telah menjadi komponen penting dalam pengajaran di universitas (S. R. Harandi, 2015).

Cara pembelajaran daring yang tertabatas hanya pada akses menyebabkan aktivitas pembelajaran terjadi tanpa batas waktu dan setiap saat mahasiswa dapat memasuki cara tersebut, berdiskusi, penyampaian dokumen dalam bentuk teks dan bagi para dosen dapat memberikan nilai dan memberikan pengumuman kapan pun dan dimana pun kepada mahasiswa. Dalam pendidikan, web (World-Wide-Web) biasanya telah digunakan sebagai sumber informasi atau bahkan sebagai perangkat pembelajaran (mahieu \& wolming, 2013).

Dengan E-Learning diharapkan proses belajar dan mengajar tetap dapat berjalan dengan baik, kapan dan dimanapun berada tanpa batasan, ruang , waktu dan terjangkau baik dari segi biaya maupun penggunaan transportasi.

Tujuan penelitian ini adalah untuk menganalisis metode pembelajaran daring terhadap motivasi belajar mahasiswa pada masa wabah covid-19 di fakultas ekonomi dan bisnis Universitas Winaya Mukti.

\section{KAJIAN LITERATUR}

e-learning sebagai sembarang pengajaran dan pembelajaran yang menggunakan rangkaian elektronik (LAN, WAN, atau internet) untuk menyampaikan isi pembelajaran, interaksi, atau bimbingan (yazdi, 2012).

e-learning sebagai kegiatan belajar asynchronous melalui perangkat elektronik komputer yang memperoleh bahan belajar yang sesuai dengan kebutuhannya (yazdi, 2012). Atau e-learning didefinisikan sebagai berikut : e-Learning is a generic term for all technologically supported learning using an array of teaching and learning tools as phone bridging, audio and videotapes, teleconferencing, satellite transmissions, and the more recognized web-based training or computer aided instruction also commonly referred to as online courses (soekartawi, haryono dan librero, 2002)

Pembelajaran dalam jaringan merupakan upaya pembelajaran menggunakan sistem teknologi berbasis elektronik atau website. Dengan menggunakan personal computer atau (PC) sebagai penggunaan media elektronik. Dengan demikian menyebabkan 
memanfaatkan dalam bentuk jaringan elektronik atau web. Dimana cara daring terbatas terhadap kemudahan dalam interaksi, oleh karenanya menyebabkan pembelajaran pada pendidikan tinggi dilakukan dengan jumlah kesempatan yang lebih besar lagi tanpa batas waktu sesuai dengan kebutuhan dari para pengguna dalam jaringan tersebut.

Ada banyak definisi untuk e-learning dari kamus Pendidikan: "E-Learning mengidentifikasi berbagai jenis pembelajaran berbantuan komputer, biasanya menggunakan sarana teknologi modern. E-learning berkembang terutama dalam bidang pendidikan jarak jauh dan pelatihan perusahaan (Prucha, 2003), Atau definisi selanjutnya:

"E-learning dapat dipahami sebagai proses pendidikan, menggunakan informasi dan komunikasi untuk membuat pelatihan, untuk mendistribusikan konten pembelajaran, komunikasi antara siswa dan guru dan untuk manajemen studi (Wagner ,2005).

E-learning merubah cara tradisional pelatihan dan pembelajaran, dan memberikan solusi baru untuk masalah. Misalnya, peran guru mungkin berubah dari importir pengetahuan ke ekspeditor pengetahuan (haverila dan barkhi, 2009). Dan itu bisa menjadi praktik pembelajaran yang sangat baik yang dapat melebihi pendidikan yang dilakukan di ruang kelas. Ini adalah pembelajaran yang mandiri dan aktif obringer (2002). Dan juga, E-learning menggunakan berbagai jenis alat pendidikan dalam belajar dan mendidik. Elearning memiliki arti yang sama dengan "learning-enhanced learning (TEL), Instruksi berbasis computer (CBI), pelatihan berbasis komputer (CBT), instruksi berbantuan komputer atau instruksi berbantuan komputer (CAl), pelatihan berbasis internet (IBT), pelatihan berbasis web (WBT), pendidikan online, virtual pendidikan, lingkungan belajar virtual (VLE) (yang juga disebut platform pembelajaran), m-learning, dan kolaborasi pendidikan digital (lihitkar, s., anilkumar naidu, s. and s. lihitkar, r., 2013).

E-learning dapat merujuk pada pengaturan pembelajaran yang berbeda, e-learning mencangkup hampir semua lingkungan belajar di mana media elektronik, seperti komputer, digunakan sebagai bagian dari sistem pendidikan.

Kelebihan E-Learning diantara-Nya yaitu: Pertama, memiliki fitur e-moderating pada saat proses pembelajaran terjadi secara sederhana menggunakan jaringan elektronik secara rutin atau dapat melakukan diskusi secara terbatas baik itu tempat dan keadaan. Selain itu, dengan menggunakan sistem ini terdapat bahan ajar yang terstruktur yang memudahkan peserta didik untuk belajar. Ketiga, pada proses evaluasi, guru ataupun dosen bisa mengevaluasi materi pembelajaran setiap waktu karena materi pembelajaran tersimpan di dalam sistem (suyitno, 2012). Sedangkan menurut maldonado, paola torres. khan,feroz u., j, g moon dan j, jeung rho j. (2011). Organisasi dan lembaga pendidikan telah berinvestasi dalam informasi teknologi untuk meningkatkan pendidikan dan pelatihan melalui pembelajaran elektronik, yang dikenal sebagai e-learning (Bates, 2001). E-learning mengacu pada pendidikan dan pelatihan yang disampaikan melalui TIK (teknologi informasi dan komunikasi), yang dirancang khusus untuk mendukung pembelajaran individu atau sasaran kinerja organisasi (clark dan mayer, 2003). E-learning telah diidentifikasi sebagai enabler bagi orang-orang dan organisasi untuk mengikuti perubahan dalam ekonomi global, terutama di era internet. Menjadi ekonomis, fleksibel, dan mudah 


\section{MODEL STRATEGI E-LEARNING TERHADAP MOTIVASI BELAJAR MAHASISWA DI MASA WABAH COVID-19}

dikirim tanpa kendala waktu dan jarak (carey dan blatnik, 2005), e-learning merupakan pilihan yang menarik bagi negara berkembang.

e-learning dapat memberikan kontribusi yang besar dalam proses pembelajaran yang dapat dikembangkan lebih luas lagi tidak hanya pada saat covid 19 melainkan pada kegiatan perkuliahan secara normal. Untuk meningkatkan motivasi pembelajaran mahasiswa di lingkungan Fakultas Ekonomi dan Bisnis universitas winaya mukti kontribusi yang tidak terlalu besar dalam e learning dipengaruhi berbagai faktor anatara lain psikologis mahasiswa, sulitnya jangkauan sinyal dalam teknologi informasi internet, masih lemahnya pengetahuan dalam teknologi internet maupun faktor keadaan keuangan dan faktor lainnya.

Menurut emda (2017) Motivasi belajar merupakan sesuatu keadaan yang terdapat pada diri seseorang individu dimana ada suatu dorongan untuk melakukan sesuatu guna mencapai tujuan. emda (2017) mengatakan Pandangan modern tentang proses pembelajaran menempatkan motivasi sebagai salah satu aspek penting dalam membangkitkan motivasi belajar siswa. emda (2017) Motivasi adalah serangkaian usaha untuk menyediakan kondisi-kondisi tertentu, sehingga seseorang mau dan ingin melakukan sesuatu dan bila tidak suka maka akan berusaha untuk meniadakan atau mengelakkan perasaan tidak suka itu. Jadi motivasi dapat dirangsang oleh faktor dari luar, tetapi motivasi itu tumbuh di dalam diri seseorang. Lingkungan merupakan salah faktor dari luar yang dapat menumbuhkan motivasi dalam diri seseorang untuk belajar.

Siswa yang termotivasi secara ekstrem cenderung mengedepankan jumlah perjuangan paling sedikit yang diperlukan untuk mendapatkan hadiah terbanyak Afzal et al., (2010).

Peserta didik yang memiliki motivasi memiliki beberapa ciri-ciri diantara-Nya: adanya sebuah keinginan untuk dapat berhasil dalam hidupnya, dan memiliki dorongan untuk belajar dan memiliki rasa penting penting untuk belajar. Menurut fauziah, amni. rosnaningsih, asih dan azharmaka, samsul (2017) seorang guru harus bisa membangkitkan dan meningkatkan minat belajar dan motivasi belajar siswa agar proses pembelajaran menjadi efektif dan mendapat hasil belajar yang diinginkan. Masih menurut fauziah, amni. rosnaningsih, asih dan azharmaka, samsul (2017:49) karena minat dan motivasi merupakan hal yang paling penting dalam diri setiap manusia supaya terpacainya tujuan yang dituju oleh seseorang, terutama pada dalam diri siswa untuk mempunyai rasa semangat yang tinggi untuk belajar dan meraih prestasi yang baik. Menurut maldonado, paola torres. Khan,Feroz U., J, G Moon \& J, Jeung Rho J. (2011). Motivasi intrinsik berasal dari penghargaan yang melekat pada tugas atau kegiatan (Ryan dan Deci, 2000a, b) sementara motivasi yang datang dari luar merupakan pelaku terutama ekstrinsik (Pintrich dan Schunk, 2002). Kesamaan antara ekspektasi kinerja, ekspektasi usaha, dan konstruk motivasi telah diamati dalam penelitian sebelumnya (Davis et al., 1989; Thompson et al., 1991; Moore dan Benbasat, 1991). Motivasi dan harapan kinerja membangun konsep ini yaitu kegunaan dan motivasi ekstrinsik, kegunaan dan harapan hasil, kepuasan dan keyakinan tentang kemampuan seseorang, dan keyakinan tentang pencapaian keuntungan. 


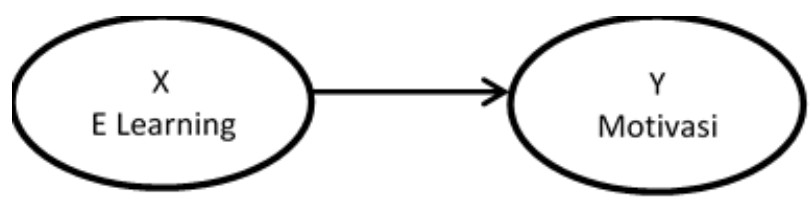

Gambar 1. Kerangka Pemikiran

\section{METODE PENELITIAN}

Metode yang digunakan dalam pengkajian materi ini menggunakan data primer yaitu berupa studi lapangan dengan melakukan proses wawancara dengan enduser serta kuesioner dan data sekunder berupa studi kepustakaan (Library) dan browsing melalui internet serta beberapa artikel jurnal. Pengkajian dengan jumlah populasi 200 rang mahasiswa di Fakultas Ekonomi dan Bisnis Universitas Winaya Mukti yang dilakukan selama wabah covid-19 yaitu bulan Februari - Mei 2020. Penelitian ini dilakukan dengan menggunakan metode sensus dengan menyebarkan kuesioner on line kepada seluruh mahasiswa, dari 200 kuesioner yang disebarkan, jumlah yang kembali sejumlah 106 kuesioner.

Alat statistik yang digunakan pada pengkajian artikel ini yaitu korelasi pearson serta regresi linier sederhana untuk mengetahui hubungan antara variabel e learning dan motivasi belajar. Data diolah dengan menggunakan SPSS 22 for windows.

\section{HASIL DAN PEMBAHASAN}

Dalam penelitian ini digunakan kuesioner dengan 43 pertanyaan yang terdiri dari 18 indikator pertanyaan $\mathrm{e}$ learning dan 25 indikator pertanyaan motivasi belajar. Kuesioner menggunakan skala likert yang terdiri dari 1 sampai 5 dimana 1 artinya sangat tidak setuju, 5 berarti sangat setuju sekali. Untuk melakukan uji Reliabilitas kuesioner dilakukan dengan menggunakan analisis Cronbach alpha diperoleh nilai reliabilitas variabel e learning 0,656 dan variabel motivasi 0,756 . Nilai reliabilitas dapat dilihat di tabel 1. Pengkajian ini membuktikan hipotesis juga menggunakan uji hipotesis yaitu dengan cara melakukan uji t.

Tabel 1. Nilai Reliabilitas

\begin{tabular}{|l|l|l|}
\hline Variabel & Nilai & Items \\
\hline $\begin{array}{l}\text { E } \\
\text { Learning }\end{array}$ & 0.656 & 18 \\
\hline Motivasi & 0.756 & 25 \\
\hline
\end{tabular}

Pengujian validitas memperlihatkan nilai Corrected Item-Total Correlation ( $r$ hitung) dimana tiap pertanyaan memiliki jumlah skor yang diperoleh dari nilai $r$ tabel 0,1591. Dengan demikian kuesioner yang dibagikan untuk setiap responden variabel motivasi belajar dapat dinyatakan valid dan layak sebagai alat ukur dalam analisis data berikutnya. Hasil Validitas secara keseluruhan terlihat pada tabel 2 dan 3.

Tabel 2. Variabel $X$

\begin{tabular}{|c|c|c|}
\hline Variabel & R hitung & kriteria \\
\hline $\mathrm{X} 1$ & 0.387 & Valid \\
\hline $\mathrm{X} 2$ & 0.256 & Valid \\
\hline $\mathrm{X} 3$ & 0.397 & Valid \\
\hline $\mathrm{X} 4$ & 0.251 & Valid \\
\hline $\mathrm{X} 5$ & 0.229 & Valid \\
\hline $\mathrm{X} 6$ & 0.287 & Valid \\
\hline $\mathrm{X} 7$ & 0.261 & Valid \\
\hline $\mathrm{X} 8$ & 0.192 & Valid \\
\hline $\mathrm{X} 9$ & 0.363 & Valid \\
\hline $\mathrm{X} 10$ & 0.439 & Valid \\
\hline $\mathrm{X} 11$ & 0.304 & Valid \\
\hline $\mathrm{X} 12$ & 0.326 & Valid \\
\hline $\mathrm{X} 13$ & 0.333 & Valid \\
\hline $\mathrm{X} 14$ & 0.263 & Valid \\
\hline $\mathrm{X} 15$ & 0.402 & Valid \\
\hline $\mathrm{X} 16$ & 0.458 & Valid \\
\hline $\mathrm{X} 17$ & 0.425 & Valid \\
\hline $\mathrm{X} 18$ & 0.324 & Valid \\
\hline
\end{tabular}


Tabel 3. Variabel Y

\begin{tabular}{|c|c|c|}
\hline Variabel & R hitung & Kriteria \\
\hline Y1 & 0.6302 & Valid \\
\hline Y2 & 0.6931 & Valid \\
\hline Y3 & 0.4764 & Valid \\
\hline Y4 & 0.7486 & Valid \\
\hline Y5 & 0.6134 & Valid \\
\hline Y6 & 0.7873 & Valid \\
\hline Y7 & 0.6695 & Valid \\
\hline Y8 & 0.7057 & Valid \\
\hline Y9 & 0.6188 & Valid \\
\hline Y10 & 0.6188 & Valid \\
\hline Y11 & 0.7486 & Valid \\
\hline Y12 & 0.7310 & Valid \\
\hline Y13 & 0.6887 & Valid \\
\hline Y14 & 0.7437 & Valid \\
\hline Y15 & 0.6481 & Valid \\
\hline Y16 & 0.5044 & Valid \\
\hline Y17 & 0.3522 & Valid \\
\hline Y18 & 0.6929 & Valid \\
\hline Y19 & 0.6660 & Valid \\
\hline Y20 & 0.8312 & Valid \\
\hline Y21 & 0.7389 & Valid \\
\hline Y22 & 0.6808 & Valid \\
\hline Y23 & 0.6610 & Valid \\
\hline Y24 & 0.6525 & Valid \\
\hline Y25 & 0.5641 & Valid \\
\hline
\end{tabular}

Dengan menggunakan Korelasi Pearson dan regresi linier diperoleh hipotesis, dari penelitian ini yaitu hasil nilai korelasi pearson $0.553>0.05$ artinya variabel $e$ learning memiliki hubungan dengan variabel motivasi dengan tingkat hubungan berada antara $0.40-0.60$ (hubungan Sedang).

Tabel 4.Korelasi Pearson

\begin{tabular}{|c|c|c|c|}
\hline \multicolumn{4}{|c|}{ Correlations } \\
\hline & & e learning & motivasi \\
\hline \multirow[t]{3}{*}{ e learning } & P.Correlation & 1 & $.553^{* *}$ \\
\hline & Sig. 2 & & .000 \\
\hline & $\mathrm{N}$ & 106 & 106 \\
\hline \multirow[t]{3}{*}{ motivasi } & P.Correlation & $.553^{* *}$ & 1 \\
\hline & Sig. 2 & .000 & \\
\hline & $\mathrm{N}$ & 106 & 106 \\
\hline
\end{tabular}

Nilai $\mathrm{t}$ hitung untuk uji hipotesis dengan $t$ tabel. $T$ hitung $2.963>1,672$ sehingga dapat disimpulkan terdapat pengaruh antara penggunaan media pembelajaran E-Learning dengan motivasi belajar Mahasiswa.

Nilai koefisien regresi pada penelitian ini adalah 0.351 Nilai ini menyatakan bahwa setiap penambahan $1 \%$ nilai penggunaan media E-Learning maka motivasi mahasiswa akan sebesar 0,351. Hasil koefisien dan $t$ hitung keseluruhannya terdapat pada tabel 5 sebagai berikut.

Tabel 5.Koefisien

\begin{tabular}{|c|c|c|c|c|c|c|}
\hline \multicolumn{7}{|c|}{ Coefficientsa } \\
\hline & & \multicolumn{2}{|c|}{ Uns. Coefficients } & \multirow{2}{*}{$\begin{array}{l}\text { Stan. Coefficients } \\
\text { Beta }\end{array}$} & \multirow[b]{2}{*}{$t$} & \multirow[b]{2}{*}{$\mathrm{s}$} \\
\hline \multicolumn{2}{|c|}{ Model } & B & Std. Error & & & \\
\hline 1 & (Constant) & $\begin{array}{l}84.9 \\
86\end{array}$ & 16.606 & & 5.118 & .157 \\
\hline & e learning & .351 & .240 & .143 & 2.963 & .004 \\
\hline
\end{tabular}

Apabila nilai $R$ adalah 0,543 koefisien determinasi ( $R$ Square) adalah $0,543 \times 0,543=0,295$ yang artinya variabel $X$ (e learning) yaitu variabel bebas dalam menjelaskan variabel $\mathrm{Y}$ (motivasi) yaitu variabel terikat adalah sebesar $29,5 \%$. Artinya terdapat 70,5\% (100\%$29,5 \%$ ) variabel terikat yang dijelaskan oleh faktor lain. Berdasarkan interpretasi tersebut, maka e learning hanya dapat berpengaruh tehadap motivasi belajar mahasiswa 29,5\%, sisanya $70,5 \%$ dipengaruhi oleh faktor lainnya. Hasil koefisien determinasi terdapat pada tabel 6 dibawah ini.

Tabel 6.Model Summary

\begin{tabular}{|l|l|l|l|l|}
\hline \multicolumn{5}{|c|}{ Model Summary } \\
\hline Model & $R$ & R Square & R Square & Std. E Estimate \\
\hline 1 & $.543 a$ & .295 & .281 & 1.66539 \\
\hline \multicolumn{4}{|l|}{ a. Predictors: elearning } \\
\hline
\end{tabular}




\section{PENUTUP}

Keberhasilan Strategi E-Learning dalam memotivasi belajar para mahasiswa di sebuah perguruan tinggi harus didukung dengan adanya interaksi antara mahasiswa, dosen, perangkat lembaga dan sistem teknologi informasi, dengan memperhatikan beberapa faktor faktor lain seperti kondisi psikologis mahasiswa, sulitnya jangkauan sinyal dalam menggunakan teknologi jaringan internet, tidak faham dalam penggunaan teknologi informasi maupun kondisi keuangan serta faktor lainnya.

Dengan E-Learning diharapkan proses belajar dan mengajar tetap dapat berjalan dengan baik, kapan dan dimanapun berada tanpa batasan, ruang , waktu dan terjangkau baik dari segi biaya maupun penggunaan transportasi.

Melalui penelitian ini penulis mengusulkan sejumlah pendapat atau saran untuk melakukan penelitian yang lebih jauh terkait dengan pengetahuan mahasiswa mengenai teknologi informasi dan menambah jumlah populasi yang dijadikan sample dalam penelitian tersebut di beberapa perguruan tinggi nasional.

\section{DAFTAR PUSTAKA}

Alkhalifa dan Peterson. (2014). On the relationship between initial motivation, and satisfaction and performance in joint ventures. Europan Journal of Marketing. London. Emerald Library.

Aviva Aurora, Hansi Effendi (2019). Pengaruh Penggunaan Media Pembelajaran E-learning terhadap Motivasi Belajar Mahasiswa di Universitas N egeri Padang.
Araimi, A.A.A. (2013).Exploratory study on employees' motivation in the omani private banking sector. International Journal of Organization Theory \& Behavior. 16 (2) : 208-220

Budiman , Haris (2017). Peran teknologi informasi dan komunikasi dalam pendidikan. Jurnal Pendidikan Islam. 8,76-83

Dinn Wahyudi, Abduhak Ishak, Supiadi. (2006). Pengantar Pendidikan. Jakarta: Universitas Terbuka.

Emda, amna. (2017). Kedudukan motivasi belajar siswa dalam pembelajaran. Lantanida Journal. 5 (2) : 93-196

Fauziah, amni. rosnaningsih, asih dan azharmaka, samsul. (2017). Hubungan antara motivasi belajar dengan minat belajar siswa kelas iv sdn poris gaga 05 kota tangerang. Jurnal jpsd 4 (1):47-53.

Gardjito , Aldo Herlambang. Al Musadieq, Mochamad. Nurtjahjono, Gunawan Eko. (2014). Pengaruh motivasi kerja dan lingkungan kerja terhadap kinerja karyawan. Jurnal Administrasi Bisnis (JAB) 13 (1) :1-8.

Harandi, S. R. (2015).Effects of elearning on Students Motivation. Procedia Soc. Behav. Sci.

Hasan, A.,Imran, ali., Muhammad, Aslam Khan., Kashif, Hamid. (2010). A Study of University Students' Motivation and Its Relationship with Their Academic Performance, International Journal of Business and Management, 5 (4) : 80-88.

Jee, Kim Kyong., Theodore, W. Frick. (2011). Changes in Student Motivation during Online Learning, 
Journal of Educational Computing Research. 44 (1): 1 - 23.

Maldonado, paola torres. Khan,Feroz U., J, G Moon \& J, Jeung Rho J. (2011). Elearning motivation and educational portal acceptance in developing countries. Online Information Review, 35(1), 66-85.

Obringer, Lee Ann. (2002). How Elearning Works, Available: http:/ / www.howstuffworks.com/ el earningl. html.

Ramdas Lihitkar, S., Anilkumar Naidu, S. and S. Lihitkar, R. (2013), Elearning programmes in library and information science: worldwide initiatives and challenges for India, Library Hi Tech News, 30 (9) : 12-20

Sarmento, M. (2010), E-Learning as a tool to improve quality and productivity in hotels, Worldwide Hospitality and Tourism Themes, 2 (4) : 398-409.

Setiawan, Kiki Cahaya. (2015). Pengaruh motivasi kerja terhadap kinerja karyawan level pelaksana di divisi operasi PT. Pusri Palembang. PSIKISJurnal Psikologi Islami 1 (2): 43-53.

Soelaiman Sukmalana. (2009). Manajemen Kinerja, Jakarta, PT. Intermedia Personalia Utama.

Sugiyono. (2017). Metode Penelitian. Bandung: Alfabeta.

Soetrisno. (2016). Berbagai pendekatan dalam pendidikan nilai dan pendidikan kewarganegaraan. Jurnal Dimensi Pendidikan dan Pembelajaran 5:29-37.
Harandi, S. R. (2015).Effects of elearning on Students Motivation. Procedia Soc. Behav. Sci.

Waight, C.L. and Stewart, B.L. (2005). Valuing the adult learner in $\mathrm{e}$ learning: part one - a conceptual model for corporate settings, Journal of Workplace Learning. 17 ( 5/6) : 337-345

Wirawan. (2016) Evaluasi. Jakarta: Rajawali Pers.

Yazdi, Mohammad. (2012). E-learning sebagai media pembelajaran interaktif berbasis teknologi informasi. Jurnal IImiah Foristek 2, 1, 143-152. 